Portland State University

PDXScholar

$5-24-2019$

\title{
The Green Gentrification of N. Williams Avenue
}

Marcco T. Higham

Portland State University

Follow this and additional works at: https://pdxscholar.library.pdx.edu/honorstheses

\section{Let us know how access to this document benefits you.}

\section{Recommended Citation}

Higham, Marcco T., "The Green Gentrification of N. Williams Avenue" (2019). University Honors Theses.

Paper 764.

https://doi.org/10.15760/honors.782

This Thesis is brought to you for free and open access. It has been accepted for inclusion in University Honors Theses by an authorized administrator of PDXScholar. Please contact us if we can make this document more accessible: pdxscholar@pdx.edu. 


\section{Honors Thesis}

The Green Gentrification of N. Williams Avenue

Marcco Higham

An undergraduate Honors Thesis submitted in partial fulfillment of the requirements for the degree of Bachelor of Arts in University Honors and Community Development

Thesis Adviser Moriah McGrath, PhD

University Honors College

Portland State University

Winter Term 2019 


\begin{abstract}
The Albina District in North Portland, Oregon has experienced a tumultuous cycle of disinvestment, decline, and now reinvestment that has caused a shift in its racial and socioeconomic composition. As new sources of investment and capital have been introduced into this historically black neighborhood, a new housing redevelopment trend has emerged that reflects consideration towards sustainable design and "eco-conscious" lifestyles. This style of redevelopment in N. Williams Avenue caters to those with higher incomes that desire an "urban" and "sustainable" lifestyle through their housing choices. In this paper I argue that this new housing trend is a gentrifying phenomenon that establishes a pretext of environmentalism and sustainability to sell market rate housing that is largely unaffordable to the neighborhood's original residents and contributes to an ongoing pattern of displacement.

Sharon Zukin's sensitizing concepts of gentrification and the marketplace and Karen Gibson's "Bleeding Albina" form the theoretical foundation of my inquiry on this type of housing redevelopment. Discussion on how low income communities face the paradox of desiring to ameliorate their local environment but fearing the risk of gentrification and displacement following rising land value is a key consideration to this paper (Bouzarovski, S., Frankowski, J., \& Herrero, S. T. (2018), Checker, M. (2011), and Kern, L., \& Kovesi, C. (2018)). Literature on how sustainable design is overlooked in its potential to lower costs associated with affordable housing is incorporated as well (Gan, X., Zuo, J., Wu, P., Wang, J., Chang, R., \& Wen, T. (2017)).
\end{abstract}

\title{
Introduction
}

North Williams Avenue has been a distinctive and historic avenue throughout Portland's development. It is a major street within the Albina neighborhood which has undergone 
tremendous change since the early 20 th century. It has been reshaped and redefined since then socially, economically, and racially. N. Williams Ave. once symbolized the presence and influence of the Black community on Portland and still has many architectural sites that depict the cultural institutions and businesses that continue to or have served this community. With the ongoing changes to the urban landscape, shifting demographic composition, and large scale urban development, this stretch of the avenue is nearly unrecognizable to older, former residents. Gentrification is a social process and can follow major events involving disinvestment from neighborhoods, dilapidation, and then ultimately revitalization (Marcuse, 1986). This transformation through gentrification also comes at a time when consideration towards climate change and environmental degradation has put pressure on urban planners, housing developers, and government actors to respond to these concerns. New trends for multi-family housing have emerged that reflect this shift in how housing is designed and marketed. In this paper, I ask to what extent is N. Williams Avenue experiencing green gentrification by prominent and pervasive housing redevelopment trends?

To effectively measure the extent and intensity of these gentrifying forces this research article assesses the validity of green gentrification of N. Williams Ave by the following: 1 . Demographic and socioeconomic analysis of 3 census tracts; 2 . And field observation and media analysis of 6 multi-family buildings that may be indicative of green gentrification.

\section{Background and literature review}

Albina is synonymous with Portland's historic black community. The neighborhoods of Boise and Eliot were majority Black until the end of the 1990's as a culmination of Oregon's recession, disinvestment, and neighborhood instability caused many to move out if they could (Gibson, 2007). Housing policy and discrimination towards prospective homeowners in Albina 
ultimately led to dire economic conditions and the "blighted" status that Albina was known for in the 1980s. Neighborhoods were facing a lack of real estate capital to avoid abandonment and dilapidation. This quote captures the severity of the situation: "In 1987, all the banks and thrifts in Portland made just ten mortgage loans to a four-census tract area constituting the heart of the Albina community" (Gibson, 2007, p. 19). With stiff resistance from lenders even as late as 1987, Black residents interested in homeownership faced detrimental barriers to improving the neighborhood on their own accord. For those that remained, Albina suffered from high vacancy rates, predatory lending, and economic stagnation that made future community improvements difficult or largely unsuccessful.

The city of Portland made attempts to ameliorate the economic conditions of neighborhoods such as Eliot and Boise. However, most new sources of residents and capital to this neglected community originated from outsiders, not from those who were pushed out in the first place. Remaining residents felt that their efforts to improve the community were overlooked by these newcomers as Albina became more hospitable for people to live in again (Gibson, 2007, p. 19). Many newcomers were drawn to Albina's neighborhoods due to its proximity to the city center and to its historic Victorian homes, for example. While economically Albina experienced revitalization following the end of the 20th century, White people became the predominating group of Albina following this economic recovery. A drastic demographic shift occurred in which the Eliot and Boise neighborhoods went from being majority Black neighborhoods to majority White. Gibson argues that the economic conditions of Albina were the result of "deliberate decisions to deny blacks access to urban housing markets and to reinforce spatial segregation" (Gibson, 2007, p. 4.) 
Following these tumultuous changes to Albina's demographic profile, N. Williams Ave. became the site of new, large scale redevelopment the neighborhood had not seen in decades. Large apartment buildings and businesses emerged that reflect attitudes towards eco-conscious lifestyles and sustainable, urban environments. Neighborhoods such as Eliot and Boise face a new type of gentrification known by several names. Despite the lack of consensus on one specific term, it refers to the following: "ecological gentrification prioritizes profit-minded development over social equity by selectively co-opting sustainability discourses, and grassroots efforts to improve the environmental quality of neighbourhoods" (Bouzarovski et al., 2018, p. 849). What was once the center of cultural and economic Black Portland now features a new urban form that prioritizes a high quality of life through multi-modal transportation infrastructure, low carbon housing, and amenities oriented around sustainability. Green gentrification subjects neighborhoods to historic urban processes that are well-documented in urban studies discourses, but also inflicts new patterns of change given new social and cultural contexts (Checker, 2011).

What this means for N. Williams Ave. is that current understandings of gentrification may be insufficient as it grapples with a new phenomenon that is reforming urban environments. The need to expand this discourse is crucial as middle and upper income people shift away from classical forms of suburbanization towards urban lifestyles being played out on N. Williams Ave. (Rice, J. L., Cohen, D. A., Long, J., \& Jurjevich, J. R., 2019). Redlining, neighborhood decline, and opportunistic real estate speculation made the conditions of these neighborhoods prime for redevelopment. Albina's real estate market recovered, but it ultimately led to displacement and marginalization of its non-White, renting residents. A turnover of Black residents has occurred while an influx of White newcomers pursue their congruent relationship with developers that 
cater to their distinct tastes and values. This relationship is key to understanding how $\mathrm{N}$.

Williams Ave. is changing demographically and economically.

\section{Methodology}

This project studied both the 3 census tracts $(34.02,34.01$, and 22.03) in the N. Williams Corridor as well as 6 specific buildings exemplifying recent neighborhood changes. These properties are all located on N. Williams Ave. on parcels zoned for CM3 (Commercial Mixed Use 3). All properties offer at least 75 rental units or more, used phrases and terminology such as "urban", "sustainable", or "luxury" to brand their housing, and offer rental rates that are higher than the median rent for the city of Portland. These characteristics formed the criteria for new housing in Albina that could be considered evident of green gentrification.

The study is designed based on the following definition of gentrification:

1. An influx of newcomers that belong to a higher socioeconomic status;

2. An increase in land and home values;

3. Displacement of original residents that are priced out of their own neighborhoods;

4. And real estate speculation involving an increase in capital and economic activities with the promise of high returns.

The incorporation of a historical background and data on demography is essential to understanding the current conditions of this neighborhood today. Gibson's "Bleeding Albina" developed a timeline of how gentrification spread and reshaped North Portland's Albina. Since the Fair Housing Act of 1968 outlawed redlining and freed up the areas in which Black Portlanders could find housing, the year 1970 became a useful benchmark for evaluating this 
section of N. Williams Ave. The end of redlining marked a historic socioeconomic shift for Albina.

Demographic changes were analyzed for a 40 year interval between 1970 and 2010, along with data on the unemployment rate of White and Black residents; median household income; median gross rent; and median home values from the 2000-2017 American Community Surveys (ACSs). These figures were analyzed to determine whether a demographic shift had occurred in a significant way in these census tracts and to provide insight on socioeconomic changes. The statistics from the 2000-2017 ACSs were considered to investigate current potential disparities between White and Black residents of these census tracts. The unemployment rate between these two groups is one indicator of their respective economic stability as a group. Measuring the pace by which gross median rent and gross median home values has changed since 2000 can indicate how this neighborhood has changed economically. Examining the change in housing costs and changes in household incomes for White Portlanders and Black Portlanders is telling of how each group has fared given the tumultuous history of disinvestment, decline, and reinvestment in Albina.

6 new multi-family buildings were selected for analysis of promotional materials and to evaluate the discourses and framing used to promote the properties. The 6 properties involved in this study are fairly recent buildings and have established a new neighborhood character for this area in Albina. A media analysis coupled with field observation evaluated their advertising material such as signage, website information, and street level characteristics exemplifying the type of housing that is present in this neighborhood. Language and rhetoric found in this media formed the basis of what these developers, property managers, and other actors contrived as their "selling points" to persuade consumers to rent this type of housing. This media analysis involved 
isolating specific words and phrases that were incorporated into the marketing for this type of housing. These words and phrases convey an understanding between potential consumers and the housing suppliers as to what lifestyle they can offer to them in return for renting. The sensitizing concept of obtaining a particular lifestyle through the housing choices of gentrifiers are based on Zukin (1982). Assessing the message conveyed through this style of marketing and the extent by which these properties brand their housing through this theoretical framework was employed in this qualitative study. The frequency of these words and phrases was measured to produce a typology for the 6 properties on N. Williams Ave.

\section{Findings}

\section{Descriptive statistics}

Graph 1 depicts this shift in the racial composition of the 3 studied census tracts: From 1990 to 2000, the Black population declined by $30.2 \%$ in Census Tract $34.02 ; 34.1 \%$ in 34.01 ; and $37.6 \%$ in 22.03. These census tracts compose the neighborhoods of Boise and Eliot, which represented some of the most "troubled" among Portland's urban neighborhoods. During the same time frame, the White population increased by $47.4 \%$ in Census Tract 34.02 and $37.3 \%$ in 34.01 but decreased in 22.03 by $45.9 \%$ according to Graph 2 .

From 2000 to 2010, Census Tracts 34.02, 34.01, and 22.03 experienced a decrease in their Black populations by $43.6 \%, 36.6 \%$, and $9.35 \%$ respectively. This further loss of Black residents in this time period indicates that conditions, whether economic or social, still were not hospitable to this community. From 1970 to 2010, a clear trend is apparent from both Graph 1 and Graph 2 in which these census tracts experienced a profound shift in their racial compositions. By 2010, all 3 census tracts were more than 50\% White. Census Tracts 34.02 and 
34.01 experienced a demographic shift that produced nearly the inverse of their demographic profiles in 1970 .

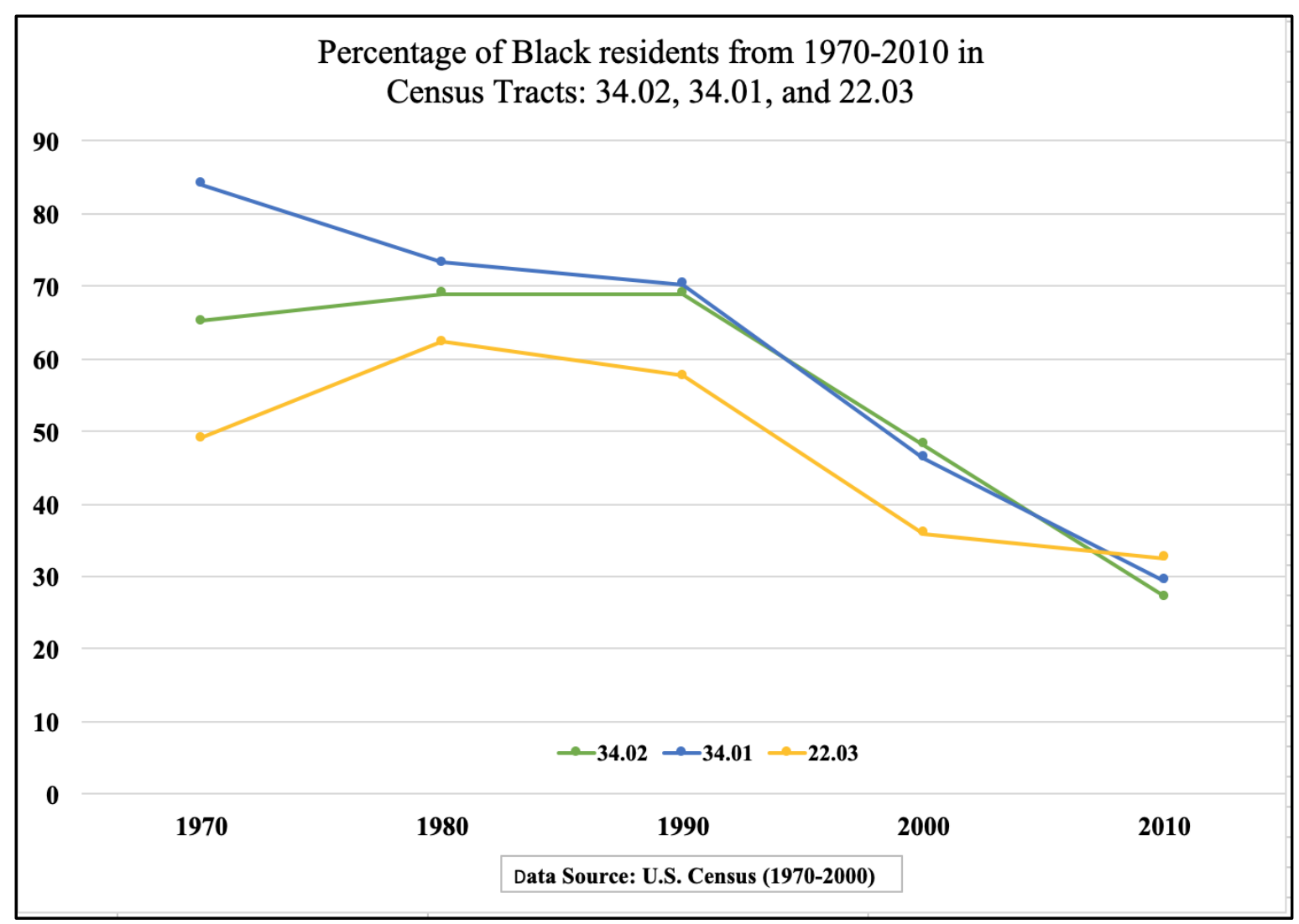

Graph 1; Data Source: U.S. Census 1970-2010. 


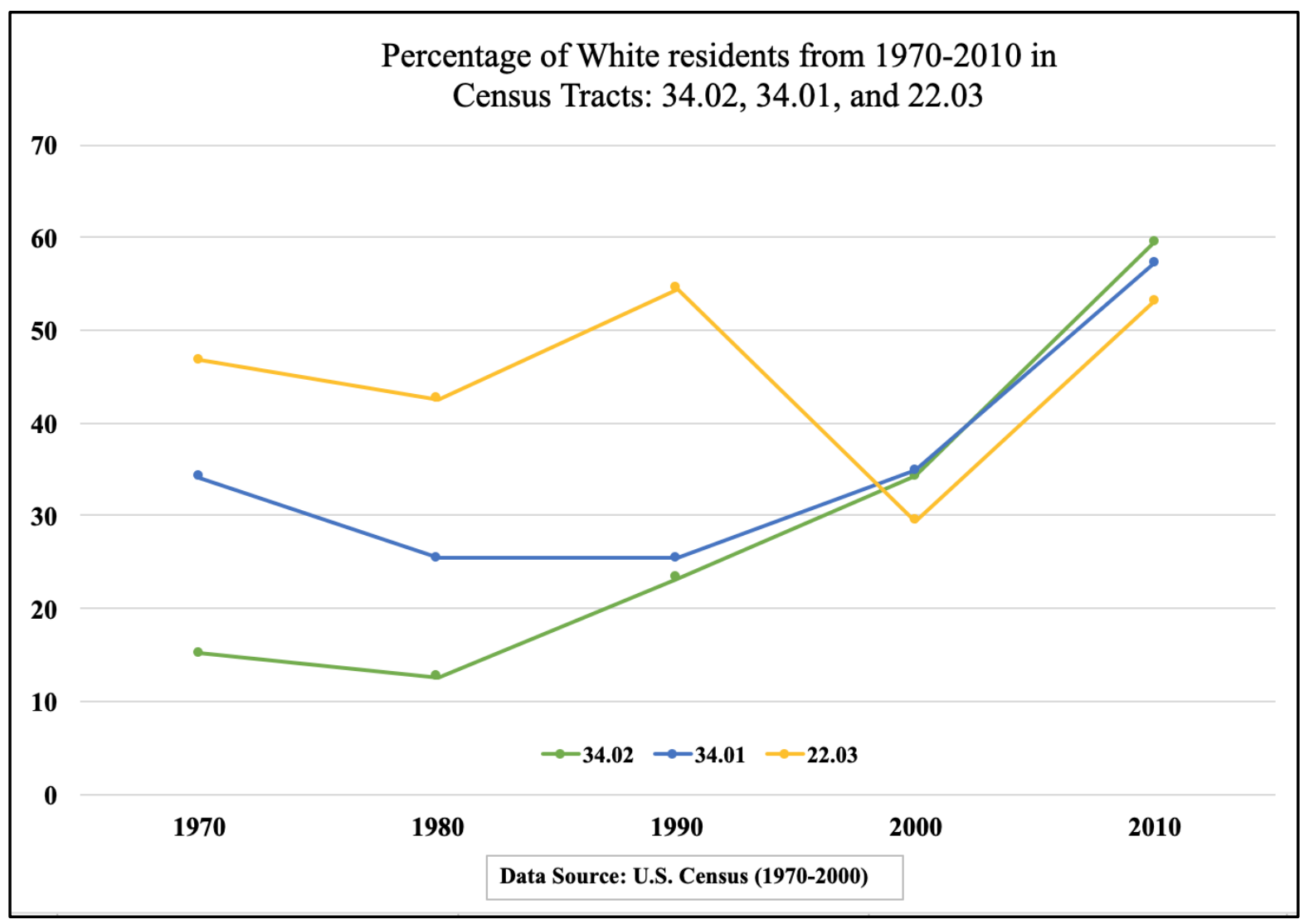

Graph 2; Data Source: U.S. Census 1970-2010.

For Census Tracts 34.02, 34.01, and 22.03, the unemployment rate for Black people 16 years old and over respectively were: $33.2 \%, 0 \%$, and 13.6\% (ACS, 2017). Their White counterparts had the following rates of: $1.5 \%, 3.2 \%$, and 5.6\%. Census Tract 22.03 did have a notable difference in the unemployment rate for both groups, Black residents 16 years old or older reported having $8 \%$ higher unemployment here. 34.02 had the most significant disparity as Black residents 16 years old and older experienced unemployment at $31.7 \%$ more than their White counterparts in 2017. Table 1 depicts the increase in median home value for each census tract and for each year selected. By 2000, evidently the conditions of the recession and blight in Albina no longer hindered gains and speculation in the housing market. In a 7 year period from 2000 to 2017 , Census Tract 34.02 increased by $269 \%$ in median home value. This intensity in median home value growth was found in 34.01 and 22.03 as well. 


\begin{tabular}{|l|l|l|l|}
\hline Median Home Value & Census Tract & Census Tract & Census Tract \\
\hline from $2000-2017$ & 34.02 & 34.01 & 22.03 \\
\hline 2000 & $\$ 112,800$ & $\$ 127,800$ & $\$ 125,000$ \\
\hline 2010 & $\$ 272,800$ & $\$ 295,500$ & $\$ 356,900$ \\
\hline 2017 & $\$ 416,700$ & $\$ 437,300$ & $\$ 480,700$ \\
\hline
\end{tabular}

Table 1; Data Source: ACS (2000, 2010, 2017)

Graph 3 depicts the median income for both Black and White households in the Boise and Eliot neighborhoods including the drastic disparity that grew between them beginning in 2000. Black households experienced meager gains in median household income while White households increasingly outpaced them. From 2000 to 2017, median income for Black households grew by $45.4 \%$ whereas White households saw theirs increase by $192.5 \%$. This is one indicator of a wealth gap between these groups and insight into the prolonged effects of prior socioeconomic conditions. 


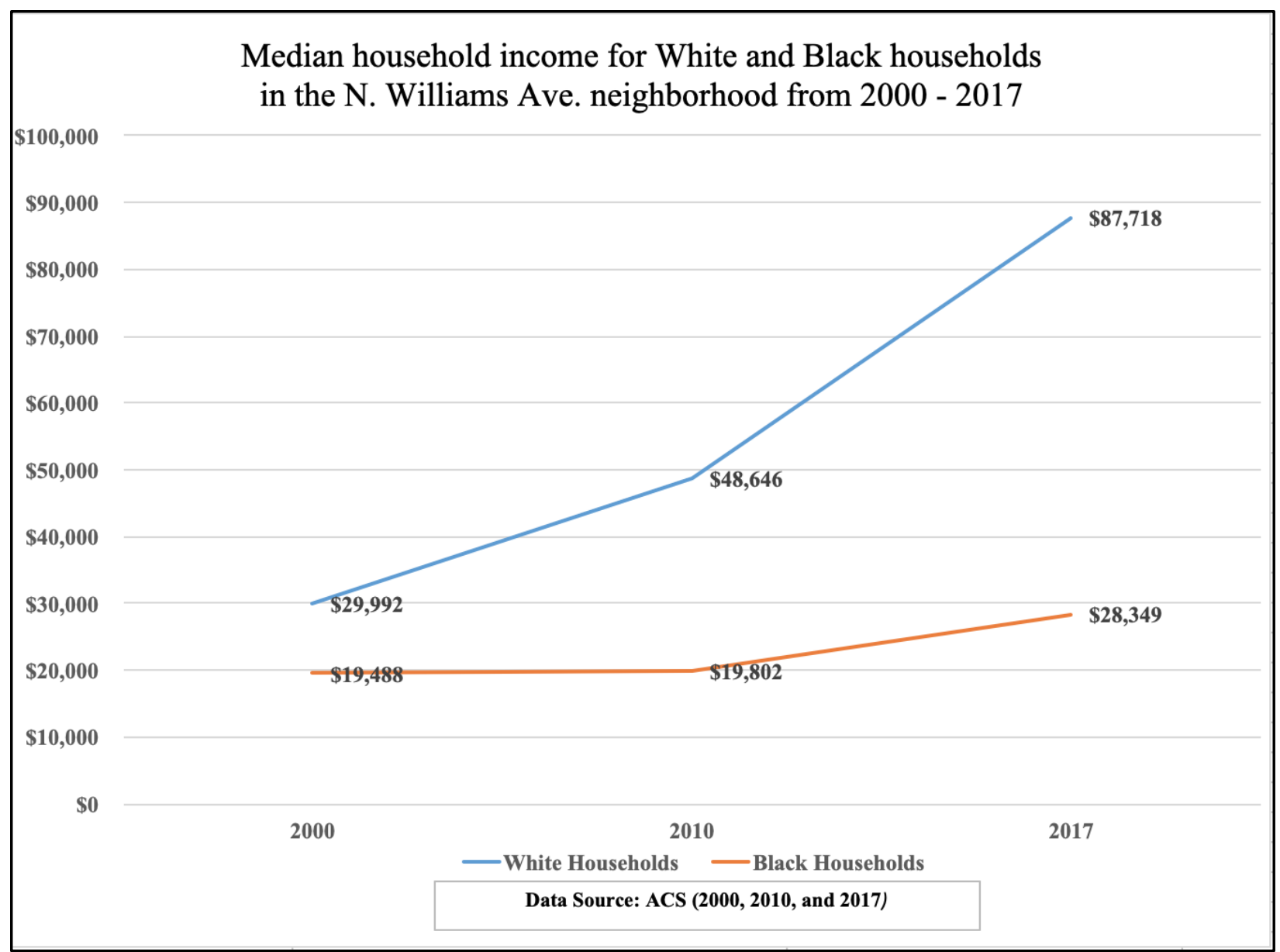

Graph 3; Data Source: ACS (2000, 2010, and 2017).

According to Graph 4, the change in gross median rent increased from 2000 to 2010, and then again from 2010 to 2017 . While this is only one metric of how census tracts are faring economically, this increase is particularly concerning given that these census tracts are composed of more renters than average for the city of Portland. In 2012, the Bureau of Planning and Sustainability of Portland created a typology map of gentrification and displacement throughout Portland. Their assessment involved four risk factors: 1 . Census tracts with more than $45.6 \%$ renters, 2. More than $27.4 \%$ of people being from a community of color, 3. Population older than 25 years old without a bachelor's degree exceeding $56.2 \%$, and 4 . More than $43.7 \%$ of households at or below $80 \%$ median family income. Census Tracts $34.02,34.01$, and 22.03 all 
had more than $45.6 \%$ of populations made up by renters. Renters in these census tracts would be more adversely affected by consecutive years of gross median rent increases than in other census tracts of the city. Moreover, Census Tracts 34.02 and 34.01 had 3 or more of the risk factors outlined in the study (Portland Bureau of Sustainability, 2012).

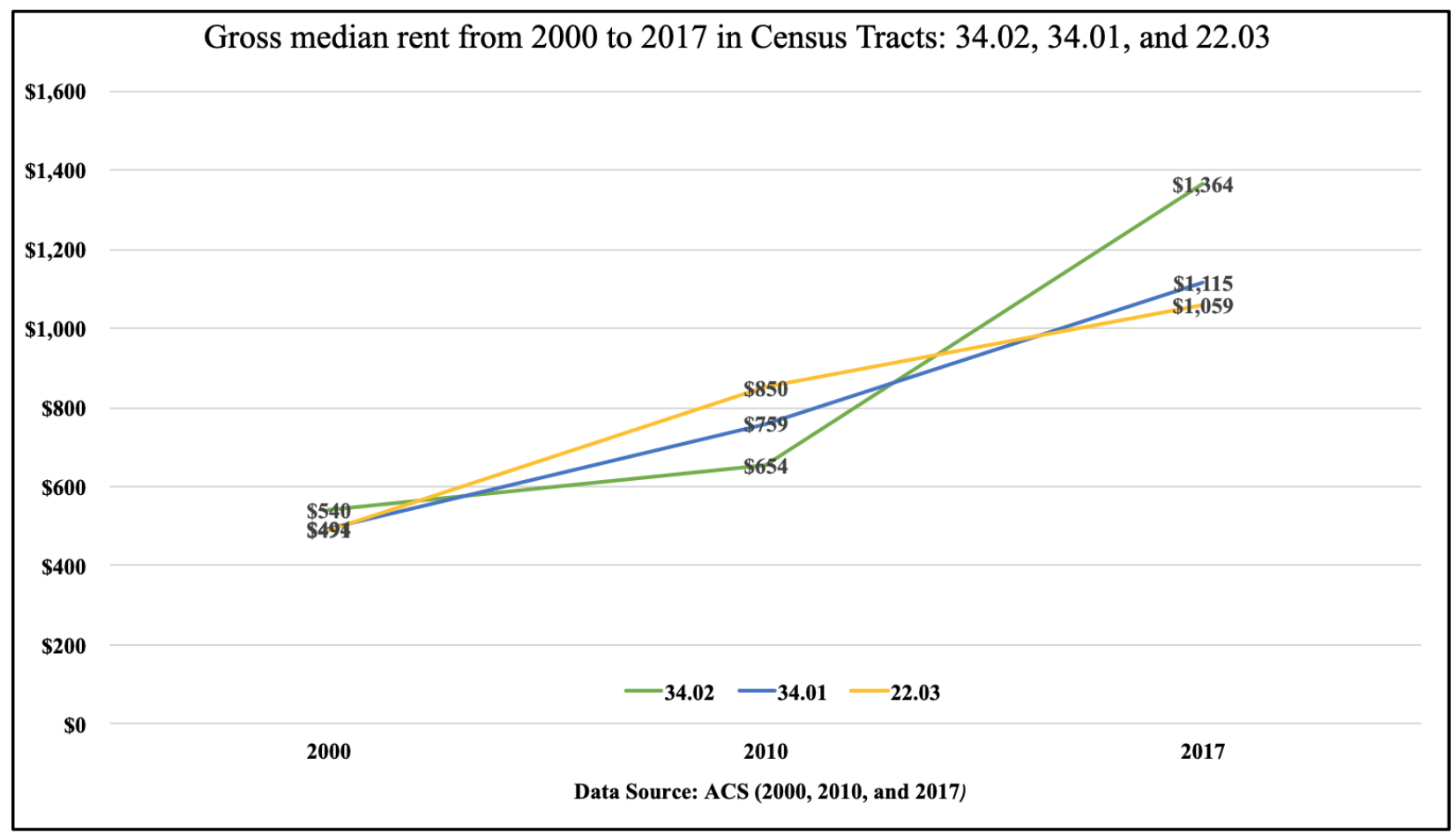

Graph 4 Data Source: ACS 2000, 2010, and 2017.

\section{Media Analysis and Field Observation}

In the present study, "urban living" and "sustainability" were the lifestyle brands on offer, summarized in Table 1. In the case of the Cook Street Apartments, The Mason Williams, and The Wilmore, their advertising language incorporated both of these themes. These 6 properties are located between N. Williams Ave. between NE Going St., marking the northern boundary, to NE Cook St., which marks the southern boundary of the study area. These themes 
of "urban" and "sustainable" living are not limited to individual apartment buildings, rather it is a common marketing strategy found in the neighborhood. According to Table 1, 4 out of the 6 sites promoted a sense of "urban" living through their promotional materials. The Mason Williams described itself as "a unique urban habitat" and the Cook Street Apartments marketed themselves "for those who think a little offbeat and appreciate the urban eclectic". The distinctive and descriptive nature of this promotional language suggests that there is a specific group of consumers they are targeting.

The other prominent theme in this media analysis is "sustainability". Table 1 demonstrates that 4 of the 6 properties feature this theme explicitly in their advertising language. Cook Street Apartments and Peloton Apartments do not explicitly state that they offer a "sustainable" lifestyle but do have language that implies this theme. This language includes “eco-friendly and crafted from natural Northwest materials" from Cook Street Apartments and "beautiful living environments that interact with activated community spaces" provided by Peloton Apartments. Sustainability as a term can be broad, but each housing property does involve this theme to some extent in their advertising language. Peloton Apartments boasts itself as a community for active lifestyles and complementary to the current biking lifestyle of N. Williams Ave (Peloton Apartments, 2019). 


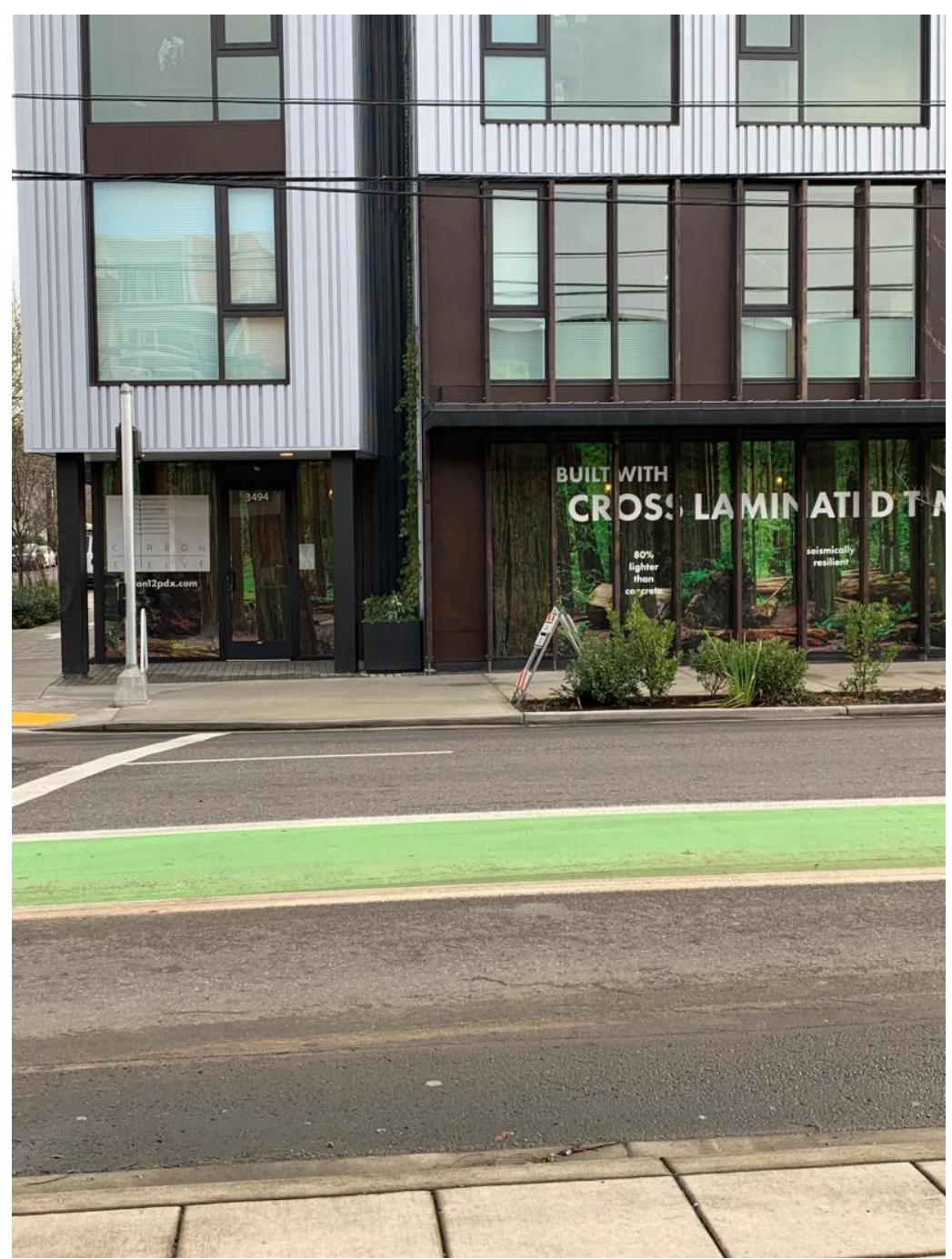

Figure 1. This image features the redevelopment trend occurring in N. Williams Ave. A bike lane and a newly constructed "boutique condo" building is pictured here (21 Jan. 2019). 


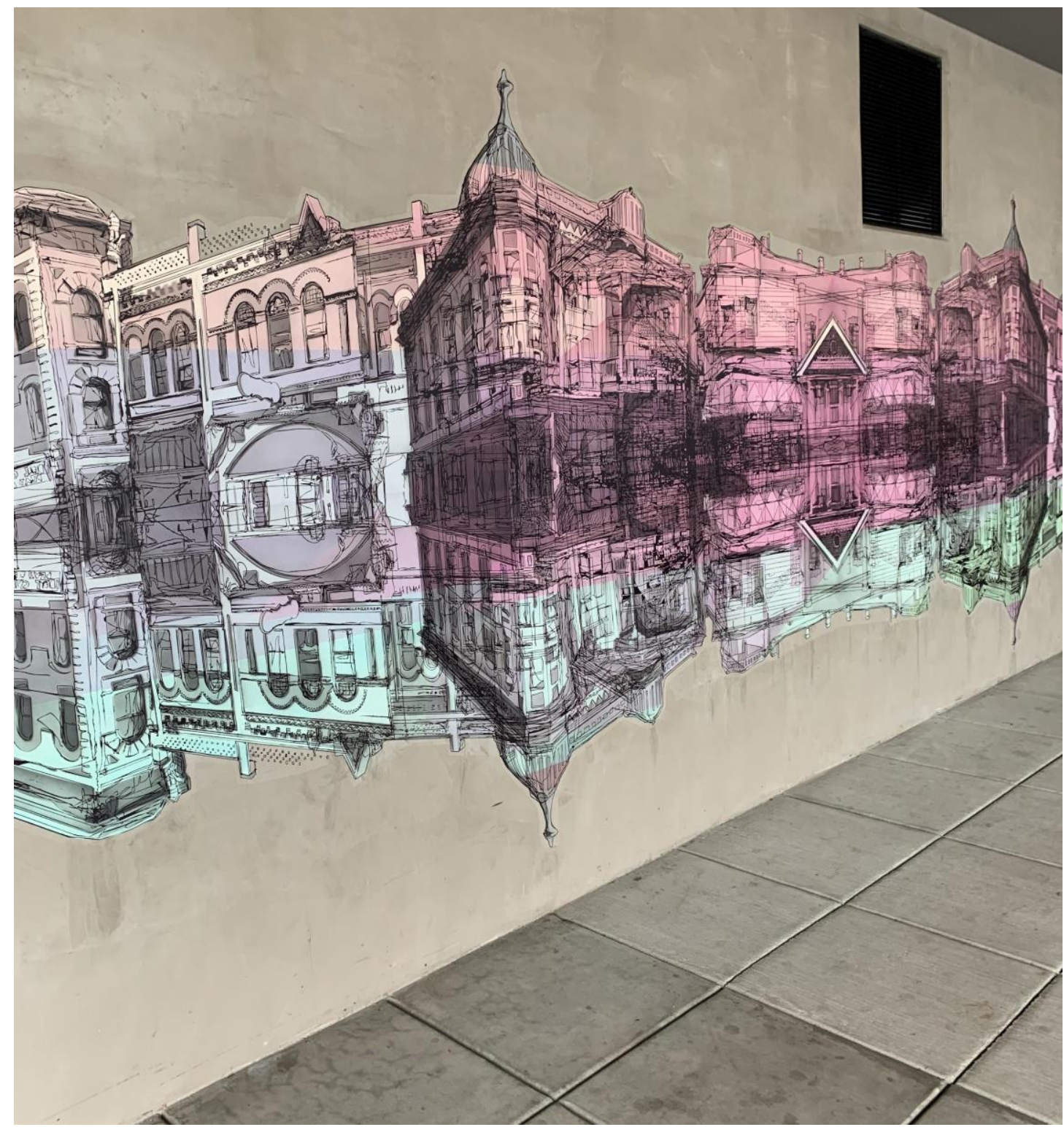

Figure 2. A mural in the Cook Street Apartments depicting the facades of Albina's historic and mostly Black-owned businesses (21 Jan. 2019).

Table 1 


\begin{tabular}{|c|c|}
\hline The Albert & $\begin{array}{l}\text { "Conscientious of your eco-friendly, sustainable lifestyle as your } \\
\text { need to get outdoors." }\end{array}$ \\
\hline Cook Street Apartments & $\begin{array}{l}\text { "Eco-friendly and crafted from natural Northwest materials." } \\
\text { "For those who think a little offbeat and appreciate the urban } \\
\text { eclectic." }\end{array}$ \\
\hline ecoFLATS & $\begin{array}{l}\text { "Net zero property focused on sustainability and efficiency." } \\
\text { "Neighbors that value sustainability as much as you do." }\end{array}$ \\
\hline The Mason Williams & $\begin{array}{l}\text { "A unique urban habitat". } \\
\text { "Eco-conscious lifestyle". } \\
\text { "Livability meets sustainability". }\end{array}$ \\
\hline Peloton Apartments & $\begin{array}{l}\text { "Community with a common perspective." } \\
\text { "Beautiful living environments that interact with activated } \\
\text { community spaces." }\end{array}$ \\
\hline The Wilmore & $\begin{array}{l}\text { "Low-key urban vibe." } \\
\text { "Ever-expanding urban bike and walk culture in Portland." } \\
\text { "Unique opportunity to live in sustainable luxury amidst an active } \\
\text { and vital neighborhood." }\end{array}$ \\
\hline
\end{tabular}

Table 2 features the "sustainable" amenities and features that justify the sustainability theme the housing properties claim. In Table 2, all properties boast that they are in close 
proximity to bike and public transit infrastructure. Another consistent feature was bike storage to ensure residents could take advantage of "the ever-expanding urban bike and walk culture in Portland" (The Wilmore, 2019). These features reflect a growing change in what developers anticipate as desired in new housing.

Table 2 demonstrates the extent to which each housing property is "sustainable". The table below includes each claim made by the studied housing properties as their sustainable amenity or feature. These incorporate the sustainable features that they deem as desirable to their young, professional clientele. Portland's rental market has established a standard for what to expect in housing that incorporates themes of being "urban" and "sustainable". While properties such as ecoFLATS, The Mason Williams, and The Wilmore do provide strong examples of their sustainability-focused technology according to Table 2, other properties do not measure up. The 3 aforementioned properties either include $L E E D$ certifications or in the case of ecoFLATS are completely net-zero. This class of housing is by many indications worthy of being considered designed with sustainability in mind. The Albert, Cook Street Apartments, and the Peloton Apartments pale in comparison. Like their counterparts, they boast bike storage and proximity to bike and public transit infrastructure. Cook Street Apartments include natural lighting and locally sourced building materials as their selling points of a sustainable lifestyle.

Table 2

\begin{tabular}{|l|c|}
\hline \multicolumn{1}{|c|}{ Housing Property } & "Sustainable" Amenity/Feature \\
\hline The Albert & $\bullet$ Bike storage. \\
& $\bullet$ Proximity to bike and public transit infrastructure. \\
\hline
\end{tabular}




\begin{tabular}{|c|c|}
\hline Cook Street Apartments & $\begin{array}{l}\text { - Natural lighting. } \\
\text { - Proximity to bike and public transit infrastructure. } \\
\text { - Locally sourced building materials. }\end{array}$ \\
\hline ecoFlats & $\begin{array}{l}\text { - Net-zero property. } \\
\text { - Hydronic heating system. } \\
\text { - Energy Star appliances. } \\
\text { - Energy efficient lighting design. } \\
\text { - Bike storage. } \\
\text { - Proximity to bike and public transit infrastructure. }\end{array}$ \\
\hline The Mason Williams & $\begin{array}{l}\text { - Green rooftops. } \\
\text { - Sustainable materials. } \\
\text { - Bike storage. } \\
\text { - } \text { LEED Gold certified. } \\
\text { - Natural lighting. } \\
\text { - Proximity to bike and public transit infrastructure. }\end{array}$ \\
\hline Peloton Apartments & $\begin{array}{l}\text { - Bike storage. } \\
\text { - Proximity to bike and public transit infrastructure. }\end{array}$ \\
\hline The Wilmore & $\begin{array}{l}\text { - Proximity to bike and public transit infrastructure. } \\
\text { - LEED Silver certified. }\end{array}$ \\
\hline
\end{tabular}




\section{Discussion}

Analyzing promotional material for the study showed the management companies' desired clientele and how this housing lifestyle being sold could be identified and evaluated. This study was coupled with a field observation of the 6 sites, the surrounding businesses, the street infrastructure, and the artwork that characterized this redeveloped neighborhood scene. The allure of gaining a lifestyle through a housing choice is a prominent theme in what was observed through the media analysis and field observation.

While this project studies new construction, there are parallels with the conversion of industrial spaces for "loft living" in the 20th century due to the persistence of the "lifestyles through housing" trend. Investigating the sudden popularity and acceptance of loft lifestyles desired by the middle and upper income classes of the United States, Zukin (1982) says that "living in a loft is a little like living in showcase". Zukin argues that lifestyle and design concepts are marketed by developers to recruit higher income residents, which leads to a higher profit margin for developers and gentrification in the neighborhood. Zukin also describes how loft living was originally sought after by artists and others who found utility in cheap, urban spaces left behind by industrialization. As the loft living trend gained traction, these spaces began to feature a more hospitable design suited for higher income residents (Zukin, 1982).

Young, working professionals in cities like Portland, Oregon are seeking out urban, mixuse places in which to live and are driving new patterns of redevelopment in neighborhoods like N. Williams Ave. This demand in the housing market works in concert with local governments and developers that encourage the supply of this housing type to draw in highly skilled, educated workers. This clientele is composed of those that "exhibit a strong desire to live in an ecofriendly urban lifestyle - and in particular a preference for urban mix-use, high-density 
developments and alternative-transit-oriented communities that allow them to walk or bike to work" (Rice et al., 2019, p. 6). Drivers of this type of redevelopment are affluent, frequently work in the technology sector, typically do not have kids, and appreciate housing that reflects the most innovative urban forms U.S. cities have to offer (Rice et al., 2019). Developers and other real estate actors are attempting to tap into this customer base. By offering numerous attractive and eco-conscious amenities, these housing consumers justify paying a premium for this housing.

This market driven relationship benefits middle to upper income, working professionals, the region's tax base, and profit making in the real estate industry. Though these themes are not uncommon in real estate marketing, a notable concentration are in close proximity to each other and developed within a few years of each other in a neighborhood that is considered vulnerable to displacement and gentrification. Census Tracts 34.02, 34.01, and 22.03 were classified as having at least 2 risk factors indicating they were vulnerable to displacement and in the case of 34.01, it had 4 risk factors (Portland Bureau of Planning and Sustainability, 2012).

Figure 2 depicts a mural in one of the sites that highlights the district's history as being the center of Black Portland before disinvestment and decline ravaged the district. While this memorializes this history, it is a harrowing reminder of the conditions that led to this style of redevelopment.

\section{Conclusion}

Green gentrification in N. Williams Ave. has embodied both historic processes of gentrification and has also produced new housing forms that bring with it new supplier and consumer relationships, redevelopment styles, and an eco-conscious pretext enveloping this urban transformation. Census Tracts 34.02, 34.01, and 22.03 are now more White and affluent 
than they have been historically. Current data on gross median rent and median home values indicate that land appreciation has made this corridor of N. Williams Ave. substantially more valuable since Albina's dilapidation and decline in the 20th century (ACS, 2017). While this paper did not assess which factors impacted the original residents the most in terms of vulnerability from gentrification and displacement, it is apparent that economic conditions are not hospitable to: 1 . non-White people, 2. renters, 3. low income households, and 4. people 25 years old and older without a Bachelor's degree in general (Portland Bureau of Planning and Sustainability, 2012).

The type of redevelopment occurring in this corridor is not reflective of the needs of its original residents, rather it is driven by a class of young, middle to upper income newcomers. These newcomers buy into the "lifestyle through housing choices" trend to achieve a lifestyle based on sustainability and urban living. This type of redevelopment exemplifies eco-conscious and low carbon design, but from the field observation and media analysis findings, several sites did not hit the mark. Rather, some ostentatiously marketed themselves based on the housing themes identified in this paper. This leads to a larger question of whether these housing themes do have sustainability objectives in mind or whether their promotional materials play into this rhetoric for the sake of selling housing.

Furthermore, redevelopment in N. Williams Ave. is overwhelmingly composed of market rate housing units. Given the rise in state-sponsored sustainable, urban development (Checker, M. (2011)) and the inaction towards incorporating sustainable design in affordable housing schemes (Gan, X., et al. (2017)), further discussion and interest is needed to understand how this development style can be made more equitable for marginalized communities. At the moment, urban, sustainable lifestyles are exclusive to those with the means to purchase them. 


\section{Annotated Bibliography}

American Community Survey. (2000, 2010, and 2017). 5-Year Estimates.

Baker, Linda. (2011). Developers Cater to Two-Wheeled Traffic in Portland, Ore. The New York Times.

https://www.nytimes.com/2011/09/21/business/portland-ore-developments-cater-to-bicycle$\underline{\text { riders.html }}$

Berkshire Communities. (2019).

https://www.berkshirecommunities.com/apartments/or/portland/cook-street/

Bouzarovski, S., Frankowski, J., \& Herrero, S. T. (2018). Low-Carbon Gentrification: When Climate

Change Encounters Residential Displacement. International Journal of Urban and Regional

Research, 42(5), 845-863. https://doi.org/10.1111/1468-2427.12634

These scholars critically assess the transitions of urban sustainability in the context of gentrification. They also look at the progressive aims of the growing awareness on climate change and how that has been appropriated into gentrifying efforts.

Checker, M. (2011). Wiped Out by the "Greenwave": Environmental Gentrification and the Paradoxical Politics of Urban Sustainability. City \& Society, 23(2), 210-229. https://doi.org/10.1111/j.1548-744X.2011.01063.X

This article investigates an interesting paradox on whether residents in a neighborhood susceptible to gentrification should reject new environmental amenities due to the risk of gentrification since these types of amenities can lead to those outcomes. Unintended consequences of environmental justice that can inadvertently lead to conditions that encourage a gentrification process to occur.

ecoFLATS. (2019). 


\section{https://www.ecoflatspdx.com/}

Eisenman, T. S. (2016). Greening Cities in an Urbanizing Age: The Human Health Bases in the Nineteenth and Early Twenty-first Centuries. Change Over Time, 6(2), 216-246.

\section{https://doi.org/10.1353/cot.2016.0014}

As a comparative study of urban municipal greening, this article examines the rise of democratic values in urban green spaces in the $19^{\text {th }}$ century and the $21^{\text {st }}$ views of green spaces on human health, urban design, and social cohesion.

Gan, X., Zuo, J., Wu, P., Wang, J., Chang, R., \& Wen, T. (2017). How affordable housing becomes more sustainable? A stakeholder study. Journal of Cleaner Production, 162, 427-437. https://doi.org/10.1016/j.jclepro.2017.06.048

Acknowledging current and historic efforts to address housing affordability, there seems to be a lack of attention towards sustainability measures and technology that can help affordability efforts. A sustainability framework for housing can include energy efficient devices/appliances, sustainable construction materials, and social sustainability such as equitable access to housing resources.

Karen J. Gibson. (2007). Bleeding Albina: A History of Community Disinvestment, 1940-2000. American Anthropological Association, 15. https://doi.org/10.1525/tran.2007.15.1.03 This paper discusses the Albina district's history of real estate disinvestment and marginalization as a community during the 20th century in Portland, Oregon. Redlining and housing discrimination are identified as key contributors to the district's decline.

Kern, L., \& Kovesi, C. (2018). Environmental justice meets the right to stay put: Mobilising against environmental racism, gentrification, and xenophobia in Chicago's Little Village. Local Environment, 23(9), 952-966. https://doi.org/10.1080/13549839.2018.1508204 
This article analyzes the impacts of environmental amelioration in small communities in the Chicago area and how they gripe with the risk of capital accumulation as a result. Community members fear that they may lose the community they worked to clean up due to the greater land value that followed and inability to afford these increased housing costs.

Mieg, H. A. (2012). Sustainability and innovation in urban development: concept and case. Sustainable Development, 20(4), 251-263. https://doi.org/10.1002/sd.471

Smith, N. (1998). Building the Frontier Myth. In The New Urban Frontier (pp. 34-40). New York, NY: Routledge.

Evaluates the "Frontier Myth" and how it romanticizes the idea of new urban frontiers to conquer and transform in a way that caters to the specific tastes of those able and desiring to gentrify.

This article discusses how sustainable planning has become a central aspect of urban planning. It questions how government and other actors will manage sustainability efforts, how resources are used to meet sustainability goals, and the dimensions sustainability occupies in society.

Peloton Apartments. (2019).

https://www.pelotonapartments.com/

Portland Bureau of Planning and Sustainability. (2012). Gentrification and Displacement Typology Assessment. https://www.portlandoregon.gov/bps/62635

Rice, J. L., Cohen, D. A., Long, J., \& Jurjevich, J. R. (2019). Contradictions of the Climate-Friendly City: New Perspectives on Eco-Gentrification and Housing Justice. International Journal of Urban and Regional Research. https://doi.org/10.1111/1468-2427.12740 
Given the rise of low carbon lifestyles and sustainable urban development, this article evaluates a contradiction that has emerged out of these trends. Residents of these "climate friendly" neighborhoods still have large carbon footprints even when energy reductions from their housing type and transportation choices are accounted for.

The Albert. (2019).

\section{http://thealbert.com/}

U.S. Census Bureau. (2019). ; generated by Marcco Higham; using American FactFinder; http://factfinder.census.gov; (12 March 2019).

The Wilmore. (2019).

\section{https://www.thewilmore.com/}

Zukin, S. (1991). Gentrification as Market and Place. In Landscapes of Power (pp. 187-195). Berkeley: University of California Press.

Characterizes gentrification as a process that reasserts a local identity onto a city center's social transformation with consideration to an international market culture.

Zukin, S. (1982). The Creation of a "Loft Lifestyle.” In Loft Living: Culture and Capital in Urban Change (pp. 58-70). Baltimore: John Hopkins University Press.

Examines the housing trend that has rebranded the urban loft lifestyle that artists and other working people once had. It also critically analyzes how these loft spaces are now deemed desirable because they have been converted to be more comfortable and suitable for people with higher socioeconomic statuses. 